\title{
Phase Equilibrium of Three Binary Mixtures Containing NO and Components Present in Ambient Air.
}

Fan Zhang $\dagger$, Elise El Ahmar $\uparrow^{*}$, Alain Valtz†, Eric Boonaert†, Christophe

Coquelet $\dagger$ Antonin Chapoy $\dagger+$

$\dagger$ MINES ParisTech, PSL - Research University, CTP - Centre of Thermodynamics of Processes,

35 rue Saint Honoré, 77300 Fontainebleau, France

$\dagger \dagger$ Hydrates, Flow Assurance \& Phase Equilibria, Institute of petroleum engineering, Heriot-Watt University

Edinburgh EH14 4AS, Scotland, United Kingdom

*Corresponding author: elise.el_ahmar@mines-paristech.fr 


\begin{abstract}
Air contains impurities, which must be removed before its transformation and utilization. In the present work, new isothermal Vapor-Liquid Equilibrium (VLE) data are reported for three binary systems containing $\mathrm{NO}$ with $\left(\mathrm{CO}, \mathrm{N}_{2}\right.$ or Ar) at different temperatures (between 105 and $146 \mathrm{~K}$ ) and pressures up to $4 \mathrm{MPa}$. The compositions of the coexisting phases were experimentally determined using an apparatus based on the "static-analytic" method. The Peng-Robinson Equation of State combined with different mixing rules (classical, WongSandler and Huron-Vidal) were used to represent the phase diagram (P, x, y).
\end{abstract}

Keywords: Vapor -Liquid Equilibrium, low temperature, thermodynamic models, measurements, phase behavior

\title{
1. Introduction
}

Air is indispensable to life and an important resource at the same time. It is approximately a ternary mixture of nitrogen, oxygen, and argon. Nevertheless, it contains variable quantities of many other substances like rare gases, COx, hydrogen, methane, oxides of nitrogen, NOx, and of sulfur, SOx. To illustrate, Table 1 gives an example of an average volumetric distribution of the substances in the air mixture. In Table 1, distinction is made between fixed components and impurities ${ }^{1}$.

Air contains large amounts of nitrogen and oxygen. Cryogenic distillation of air is the oldest but most highly developed separation technology for the industrial production of oxygen and nitrogen. This technology has not changed fundamentally from that initially developed by Carl von Linde and Claude-Delorme at the beginning of the 20th century. The core of a conventional Air Separation Unit (ASU) is a system of two distillation columns and a reboiler-condenser in between working at about $100 \mathrm{~K}$. The importance of this process depends heavily on its capability in providing extremely pure nitrogen (10 ppb of impurities) and oxygen (purity from $85 \%$ up to $99.7 \%$ ) in both the liquid and vapor states. Cryogenic air separation is based on the principle of fractional distillation. This process involves liquid and vapor phases and air components are separated on the basis of differences in boiling point and of relative volatility. Consequently, the whole process is related to the VLE occurring within the distillation column, thus important information for the plant design are saturation lines of the main air components and the thermodynamics and phase equilibria of mixtures of 
nitrogen, oxygen, and argon. There are currently few data available in the open literature on the thermodynamic behavior of mixtures composed of fixed components + impurities as well as mixtures composed of two impurities.

Since 1990's, the Centre of Thermodynamics of Processes has been involved in the study of the thermodynamic behavior (experimental measurements and thermodynamic calculation) of such mixtures. As examples of results obtained, we can mention the study of phase equilibria of several binary systems, $\mathrm{O}_{2}-\mathrm{N}_{2}, \mathrm{O}_{2}$ - $\mathrm{Ar}$ and Ar- $\mathrm{N}_{2}$ (VLE, Baba-Ahmed et al. ${ }^{2}, \mathrm{O}_{2}-\mathrm{CO}_{2}, \mathrm{O}_{2}-$ $\mathrm{N}_{2} \mathrm{O}$ (solid solubility in liquid oxygen, De Stefani et al. ${ }^{3}$ ), $\mathrm{O}_{2}$-propane (VLLE, HoussinAgbomson et al. ${ }^{4}$ ) and $\mathrm{N}_{2}$-propane (VLLE, Houssin-Agbomson et al. ${ }^{5}$ ). NO, CO and Ar are also impurities present with $\mathrm{CO}_{2}$ after the process of $\mathrm{CO}_{2}$ capture. Development of thermodynamic model to design $\mathrm{CO}_{2}$ transportation process requires binary interaction parameters (Coquelet et al. ${ }^{6}$ ). These parameters are obtained from experimental data. In this work, VLE measurements of three binary mixtures composed of some impurities (Ar-NO, CO-NO and $\mathrm{N}_{2}-\mathrm{NO}$,) will be presented at low temperature conditions. The Peng-Robinson Equation of State, commonly used in industry, is used to model the above systems.

\section{Experimental set-up}

\subsection{Chemicals}

Chemicals (nitrogen, argon, carbon monoxide and nitric oxide) were purchased from Air Liquide (France) and presented in Table 2. The chemicals were used without further purification.

\subsection{Apparatus description}

The set-up is based on the 'static-analytic' method, for measurements at temperatures down to the normal nitrogen boiling temperature. The measured properties are: pressure, temperature and vapor and liquid compositions. A Hastelloy C276 cell $\left(43 \mathrm{~cm}^{3}\right)$ is placed inside a cryostat partially filled with liquid nitrogen. If the desired temperature is the normal nitrogen boiling temperature, the cell is completely immersed in liquid nitrogen. Above this temperature, the level of liquid nitrogen is maintained below the bottom of the cell. In this way, liquid nitrogen acts as the cold reservoir while a rounded heating resistance connected to a PID thermal regulator is used to achieve temperature stability within $0.1 \mathrm{~K}$. Two capillary samplers Rapid On-Line Sampler-Injector (ROLSI $\left.{ }^{\circledR}\right)^{7}$ are fixed on the top of the cell, one for the liquid phase and one for the vapor phase, and allowing direct injection of samples into the carrier gas 
circuit of a gas chromatograph. Efficient stirring of mixtures inside the cell is achieved using a magnetic rod driven by an external rotating magnetic field. Its rotation speed is selected through a variable speed motor.

A detail description of the setup can be found in Baba-Ahmed et al. ${ }^{2}$ and Houssin-Agbomson et al. ${ }^{4}$.

\subsection{Calibrations and uncertainty estimation}

Calibration of pressure transducer is performed against a dead weight pressure balance (Desgranges \& Huot 5202S, CP 0.3-40 MPa, Aubervilliers, France). Accuracies are estimated to be within $0.005 \mathrm{MPa}$. The two platinum resistance thermometer probes $(100 \Omega)$ are calibrated by measuring the oxygen vapor pressure at low temperatures and comparing this value to the one found in the open literature. These probes are coupled to a Hewlett Packard multi-meter. Accuracies are estimated to be within $0.1 \mathrm{~K}$ for both probes. The signals from the probes (temperatures and pressures) are transmitted to a data acquisition system (DAS) which is connected to a PC. The thermal conductivity detector (TCD) of a Perichrom gas chromatograph (PR-2100) is calibrated using known amounts of compounds introduced through syringes. The column used for this analytical work is a packed column molecular sieve 5A (60/80) (Restek, France).

To estimate the uncertainties in temperature, pressure and composition, we have followed the guidelines of NIST ${ }^{8}$. The uncertainty estimation procedure is fully described by Zhang et al. ${ }^{9}$. Both measurements repeatability and calibration uncertainties are taken into account. All the expanded uncertainties $\mathrm{U}(\mathrm{x}), \mathrm{U}(\mathrm{y})$ with coverage factor, $\mathrm{k}=2$ ) for experimental data are reported in section 4 .

\subsection{Experimental procedure}

At room temperature, the equilibrium cell and its loading lines are vacuumed. The cell is first loaded with the component having the lowest vapor pressure (NO in our study). The temperature is then set to the desired point and the system is left to reach thermodynamic equilibrium. After recording the vapor pressure of this component, the second component is introduced step by step, leading to successive equilibrium mixtures of increasing overall compositions. The two-phase (liquid and vapor) envelopes are measured with about 6 to 10 liquid and vapor points. Phase equilibrium is assumed to be achieved while temperature and pressure readings stabilized for at least $30 \mathrm{~min}$. For each equilibrium condition, several samples of each phase (vapor and liquid) are withdrawn using the capillary samplers ROLSI® 
and analyzed in order to determine the mole fraction of each phase and check for repeatability of measurements which must be closed or better than $\pm 1 \%$.

\section{Modelling}

For binary mixtures modelling, the critical parameters (temperature $\left(\mathrm{T}_{\mathrm{C}}\right)$ and pressure $\left(\mathrm{P}_{\mathrm{C}}\right)$ ), and acentric factor $(\omega)$ for each of the pure components are provided in Table $3^{10}$. The experimental VLE data were correlated using the Peng-Robinson cubic Equation of State (PR EoS) ${ }^{11}$ with different mixing rules. These models were chosen in order to produce reliable correlation of the experimental data with reasonable accuracy comparable with experimental uncertainties and to represent at the best the both phases. - PR EoS incorporating the the Mathias-Copeman alpha function ${ }^{12}$, combined with the classical mixing rules ${ }^{13}$ (PR-EoS) as implemented in in-house software developed at CTP. - PR EoS incorporating the MathiasCopeman alpha function, with the Wong-Sandler mixing rules ${ }^{14}$ involving NRTL activity coefficient model $^{15}$ (PR-WS-NRTL EoS) (with non-randomness parameter $\alpha=0.3$ ).

- PR EoS incorporating the Mathias-Copeman alpha function, with the Huron-Vidal mixing rules $^{16}$ with a Wilson activity coefficient model $^{17}$ (PR-HV-Wilson EoS)

The Mathias-Copeman alpha function coefficients for all components are listed in Table $3^{10}$. Binary Interaction Parameters (BIP, kij) were determined directly from the VLE data by minimizing the following objective function (eq.1):

$$
O F=\frac{100}{N}\left[\sum\left(\frac{P_{\exp }-P_{c a l}}{P_{\exp }}\right)^{2}\right]
$$

Where P corresponds to bubble pressure, exp corresponds to experimental and cal corresponds to calculated.

\section{Results and discussion}

\subsection{VLE data for Ar-NO system}

The experimental VLE data were determined at 135.80 and 146.22 K (see Table 4) and are plotted in Figure 1. The PR-EoS using the classical mixing rules is used to represent the phase diagram $(\mathrm{P}, \mathrm{x}, \mathrm{y})$. The adjusted BIP $\left(k_{i j}\right)$ with and without a temperature dependency are presented in Table 5. 
In order to quantify the fit of the models to the experimental data, the average absolute deviation (AADU) is calculated for the pressure and the vapor phase mole fractions. The deviation is defined by:

$$
A A D U=(100 / N) \sum\left|\left(U_{\exp }-U_{c a l}\right) / U_{\exp }\right|
$$

Where $N$ is the number of data points, cal corresponds to calculated value, exp corresponds experimental value and $U=P_{l}$ or $y_{1}$.

These indicators, which give information about the agreement between model and experimental results, are presented in Table 5. Regarding these indicators, taking into account a temperature dependent BIP does not improve significantly the calculated data obtained. In Figure $1, k_{i j}$ values used for our calculations with the PR are those obtained with a temperature dependency. PR The AADU is less than $2.3 \%$.

Figure 1. Phase diagrams (P-x-y) for Ar (1) - NO (2) mixture (symbols: this work, $\square: 146.42 \mathrm{~K}, 0$ : $135.80 \mathrm{~K}$, Black lines: PR-EoS with a temperature dependent BIP).

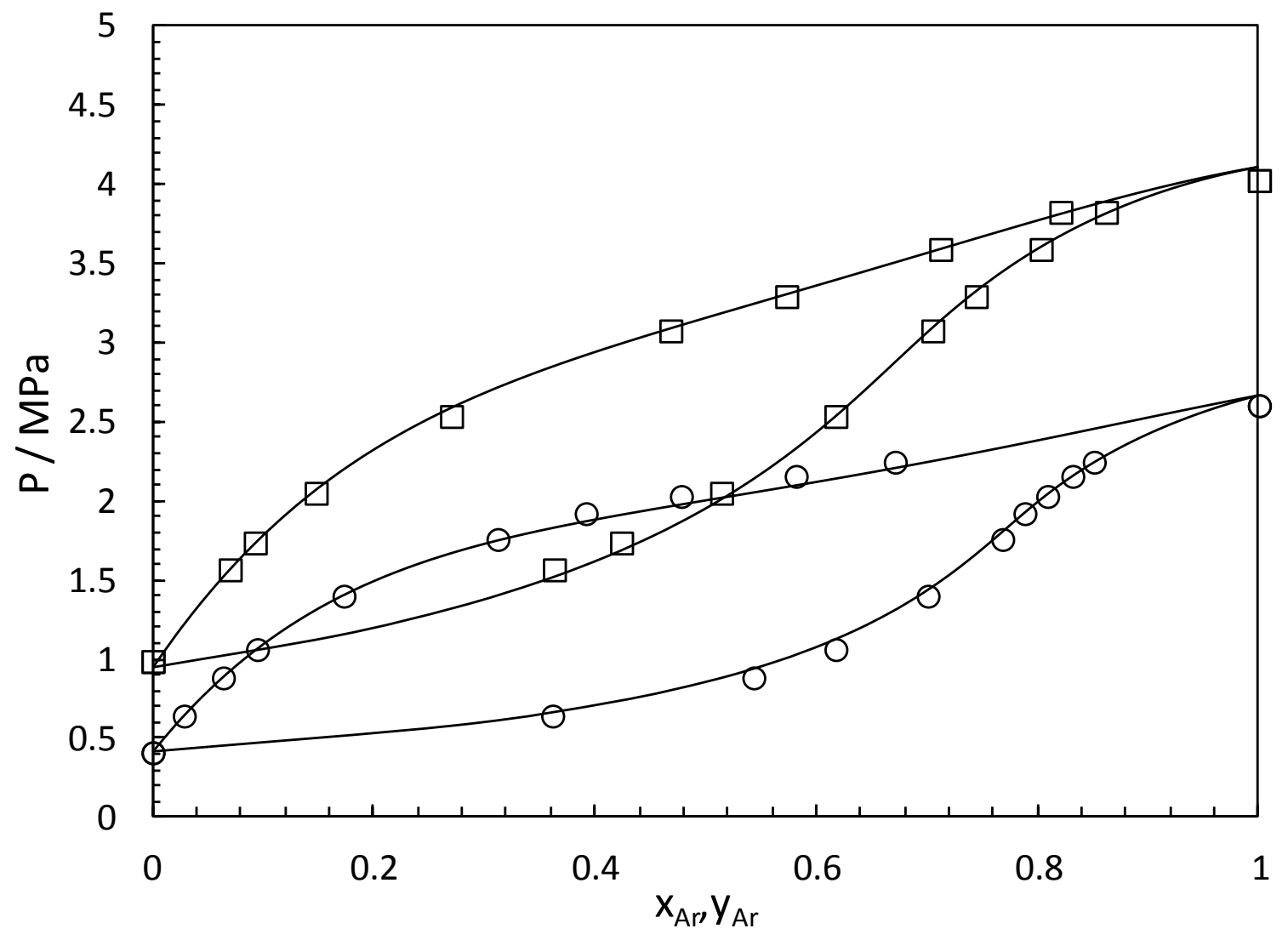




\subsection{VLE data for CO-NO system}

Table 6 and Figure 2 present the VLE data obtained at 105.89 and 127.32 K. A temperature dependent BIP to represent the experimental data was considered. (Table 7). At higher temperature the PR-EoS with the classical mixing rules have some difficulties representing the liquid composition (see Figure 2.a). In order to display a decent match with the experimental data (particularly for the liquid phase), the PR-WS-NRTL EoS (with nonrandomness parameter $\alpha=0.3$ ) was used. This model has 3 BIPs which give more flexibility to represent correctly the phase diagram of the system. With this mixing rule, the PR-EoS handles the representation of both phases (liquid and vapor) reasonably well. The AADU is less than $1.4 \%$.

Figure 2. Phase diagrams (P-x-y) for CO (1) - NO (2) mixture (symbols: this work, $\square: 127.32 \mathrm{~K}, 0$ : $105.89 \mathrm{~K}$, Black lines: PR-EoS with a temperature dependent BIP.

a- With classical mixing rule

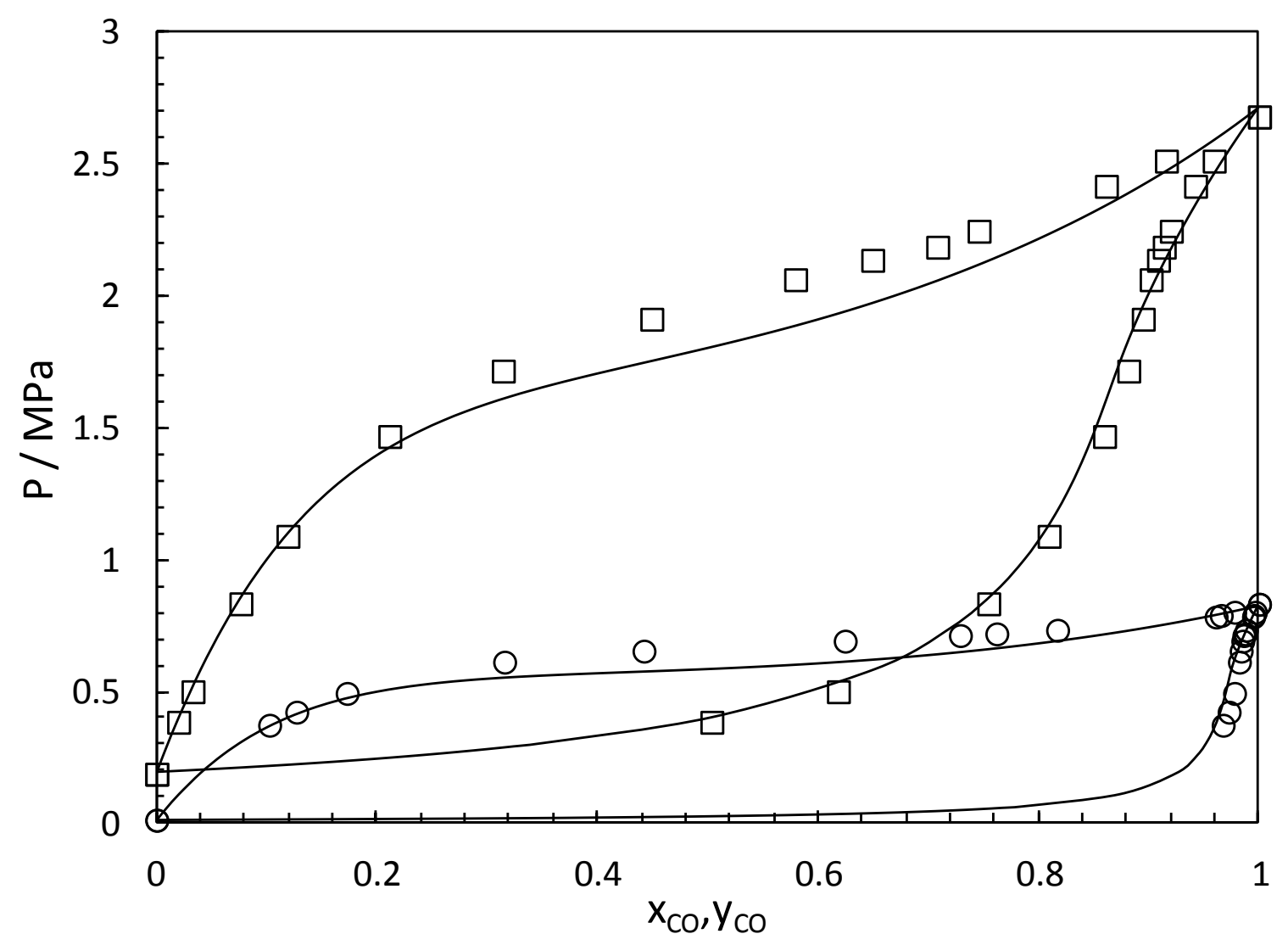


b-With Wong-Sandler mixing rule and NRTL activity coefficient model

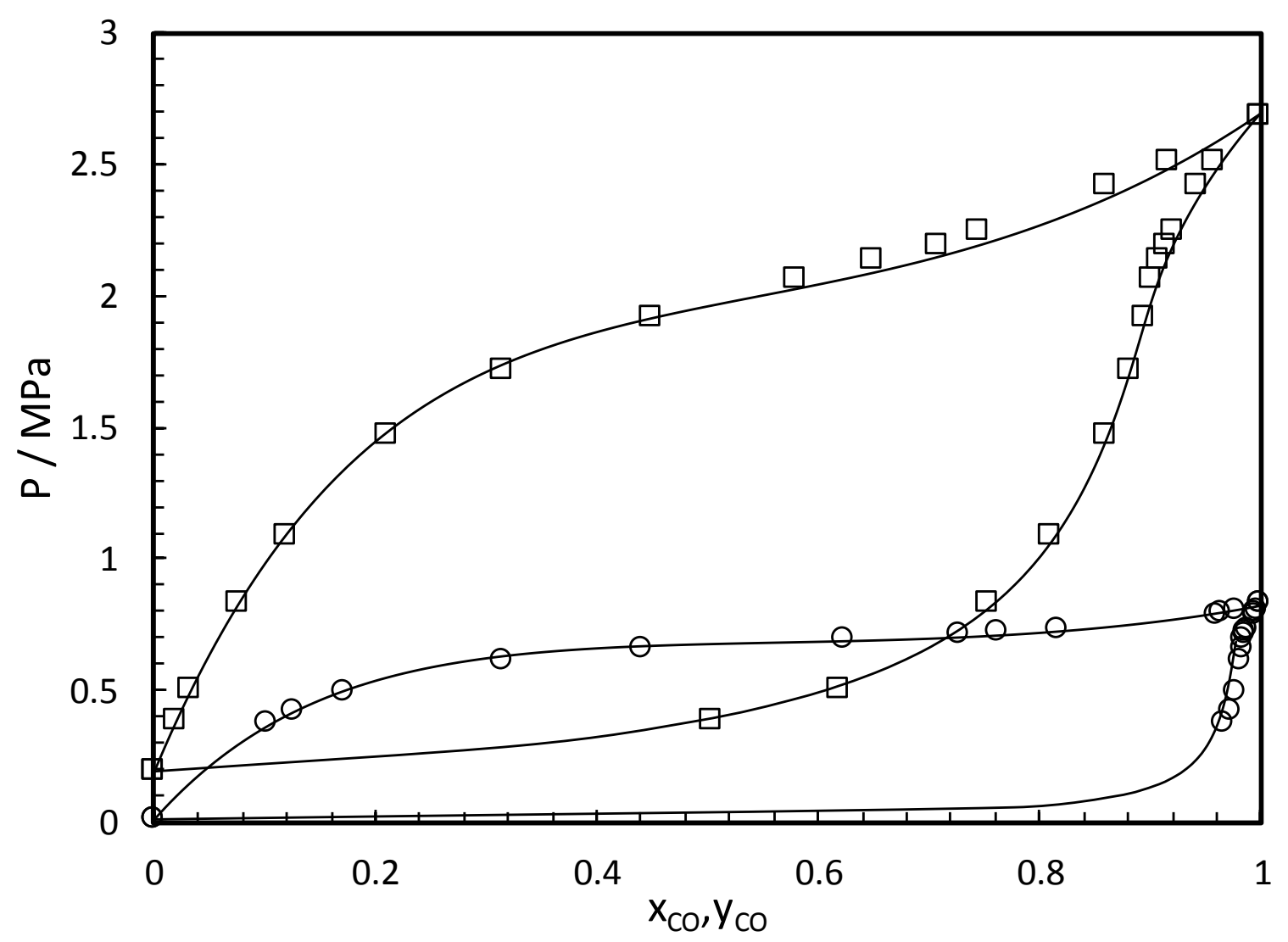




\subsection{VLE data for $\mathrm{N}_{2}$-NO system}

This system has been studied by Scheunemann et al., (1985) ${ }^{18}$ at 113.85 and 119.55 K. Our new experimental data were measured at 105.69 and $127.14 \mathrm{~K}$ (see Table 8). Table 9 presents the BIP obtained at each temperature. For this system, the PR-EoS with classical mixing rule have some difficulties in representing the liquid composition, particularly for $\mathrm{N}_{2}$ rich mixtures (Figure 3.a). A vapor-liquid-liquid-equilibrium is predicted when using the PR-WS-NRTL EoS, for the lowest temperature (Figure 3.b). To overcome this problem, the PR-HV-Wilson EoS was used. The Wilson activity coefficient model is well known not to predict liquidliquid equilibria. The PR HV-Wilson EoS model handles the representation of both phases (liquid and vapor) reasonably well (Figure 3.c). The BIP values except at $119.55 \mathrm{~K}$ are an increasing function of the temperature and follow a linear behavior (Figure 4).

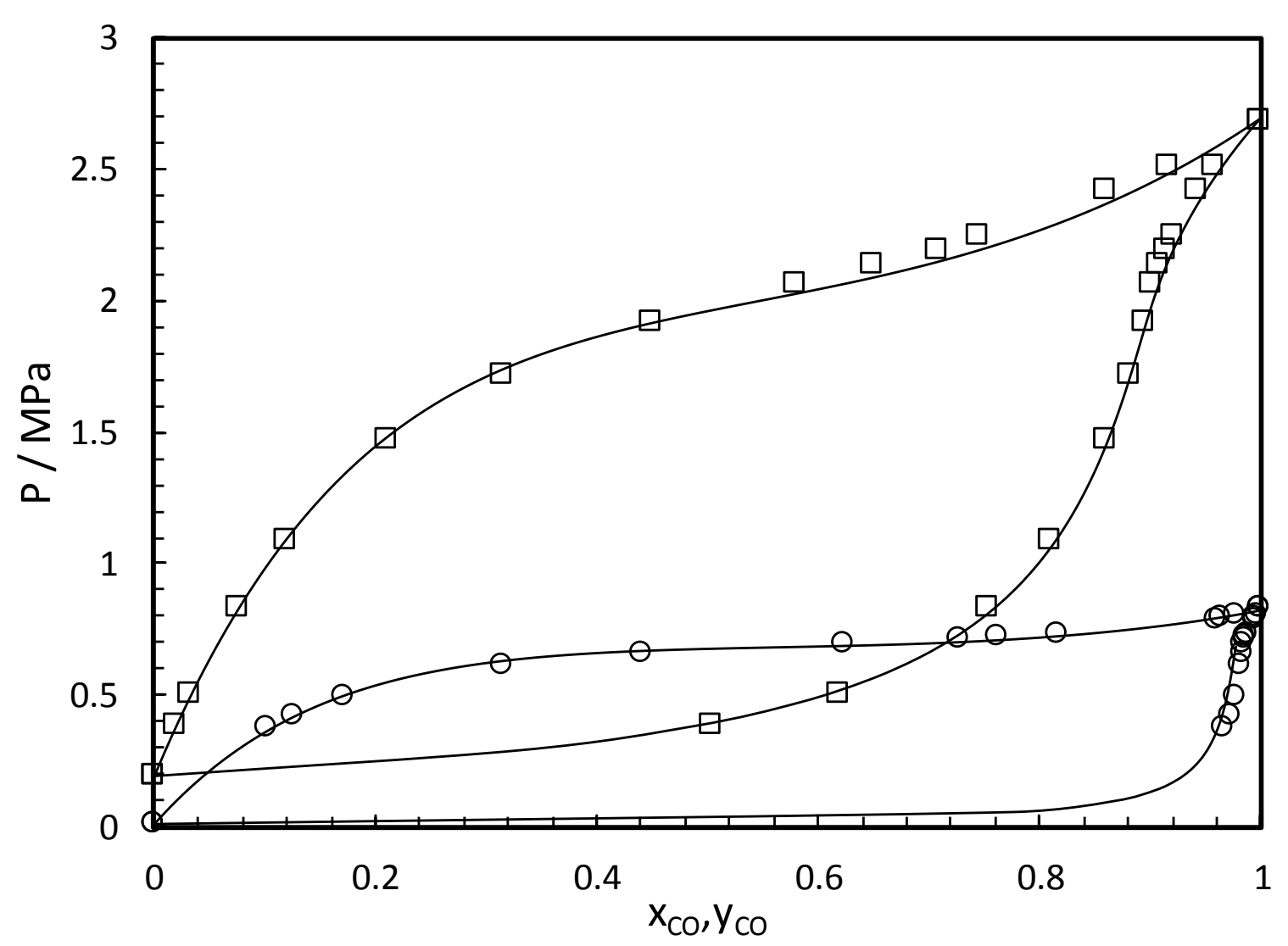


Figure 3. Phase diagrams (P-x-y) for $\mathrm{N}_{2}$ (1) - NO (2) mixture (symbols: experimental work, $\square$ : data measured in this work at $127.14 \mathrm{~K}$, ०: data measured in this work at $105.69 \mathrm{~K}$, $\times$ : Data from Scheunemann and Wagner measured at $119.55 \mathrm{~K}^{18}$, +: Data from Scheunemann and Wagner measured at $113.85 \mathrm{~K}^{18}$, Black lines: PR-EoS with a temperature dependent BIP).

a-With classical mixing rule

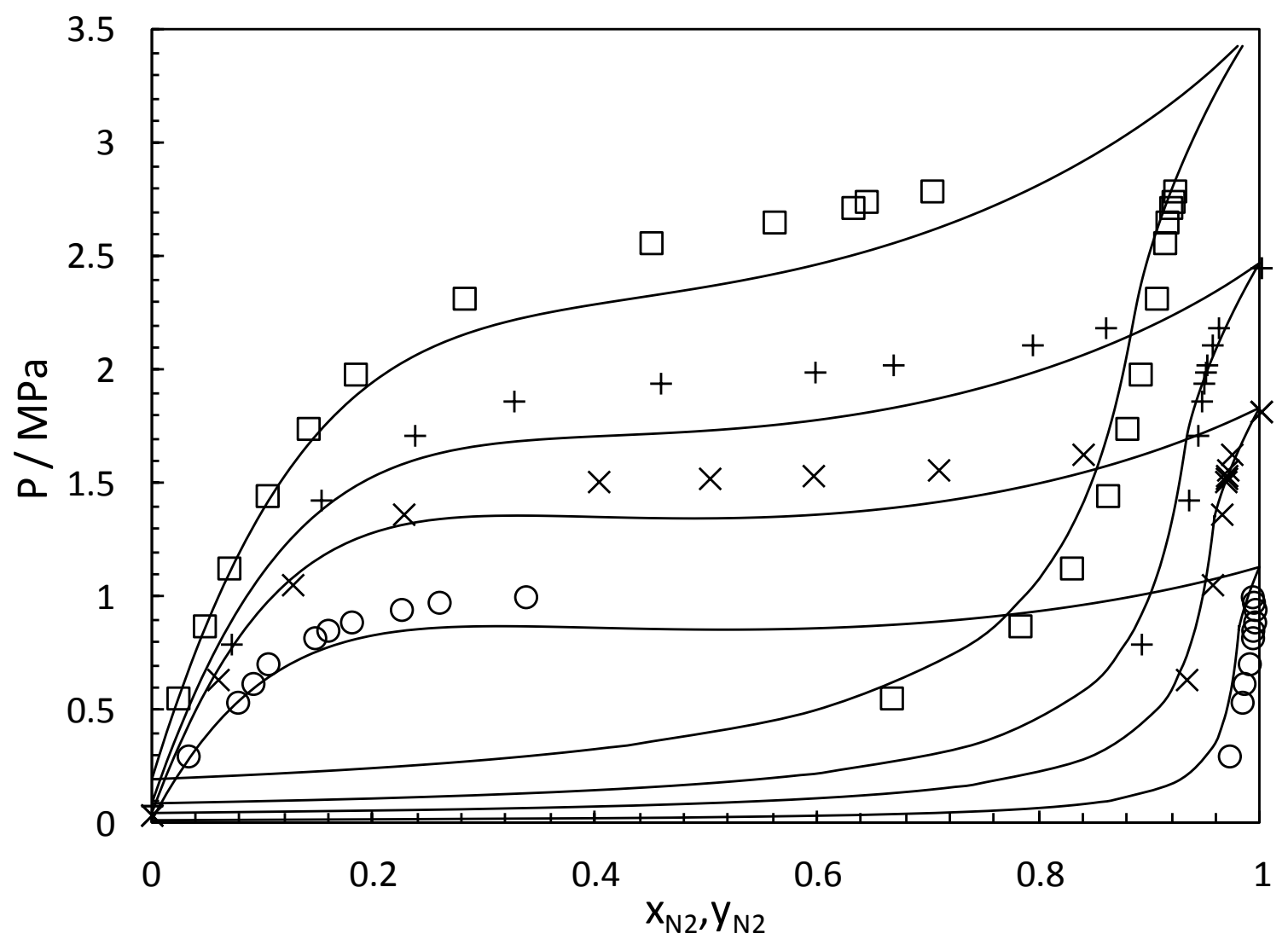


b-With Wong-Sandler mixing rule and NRTL activity coefficient model

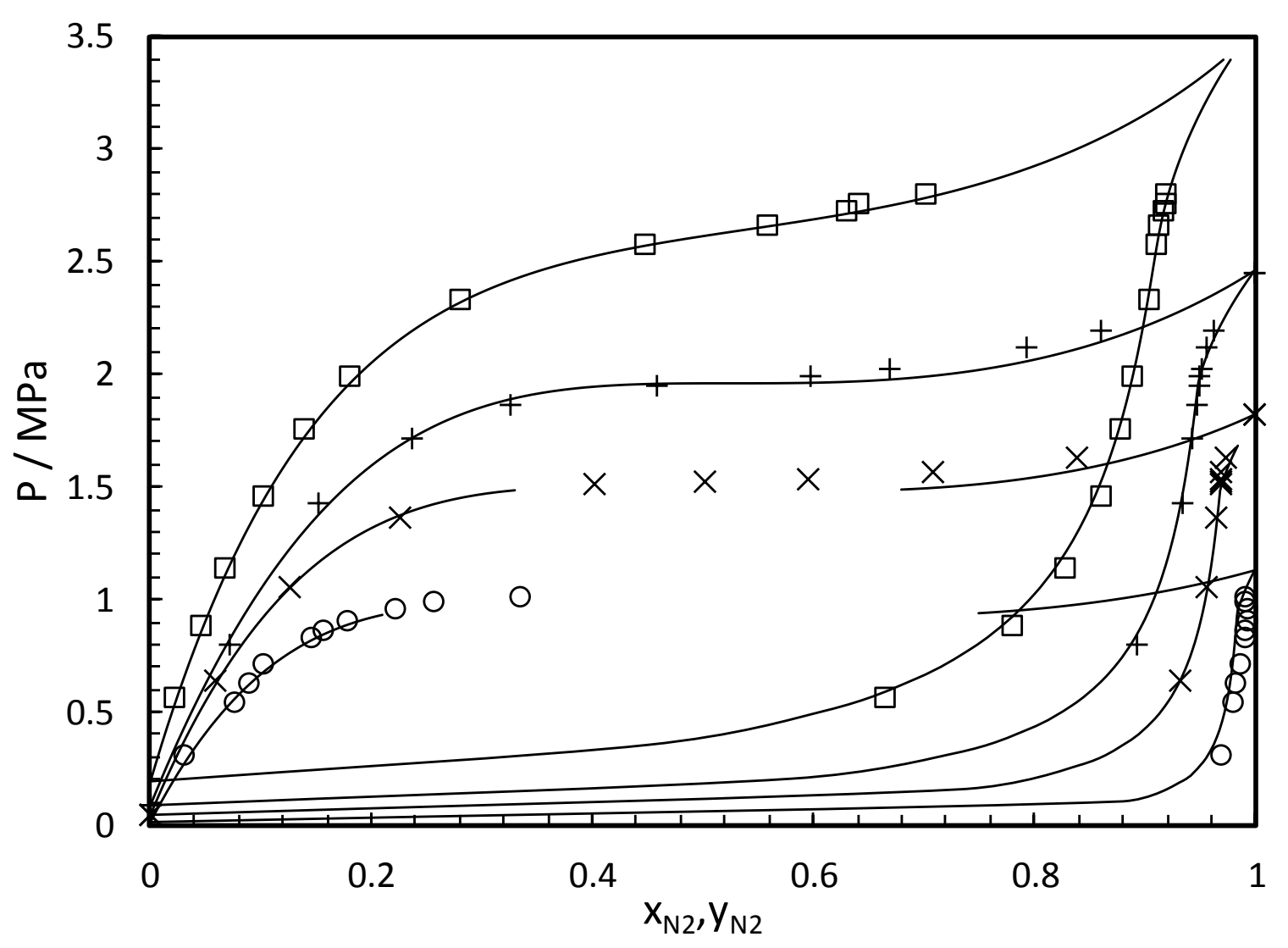


c-With Huron-Vidal mixing rule and Wilson activity coefficient model

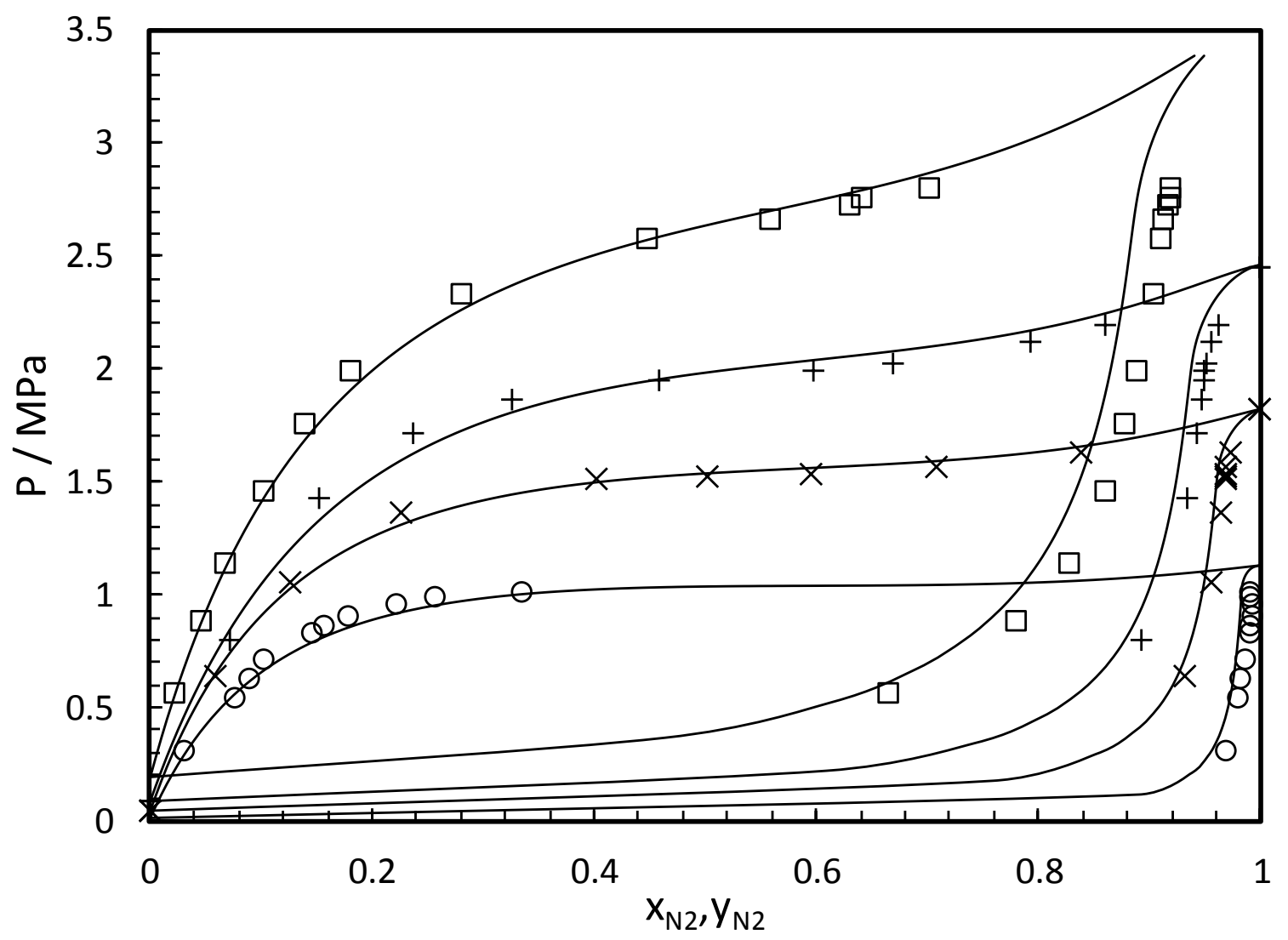


Figure 4. BIP's values with PR-WS-Wilson EoS as function of temperature. (symbols: $\circ: \tau 12, \square: \tau 21$ ) for $\mathrm{N}_{2}$ (1) - NO (2) mixture.

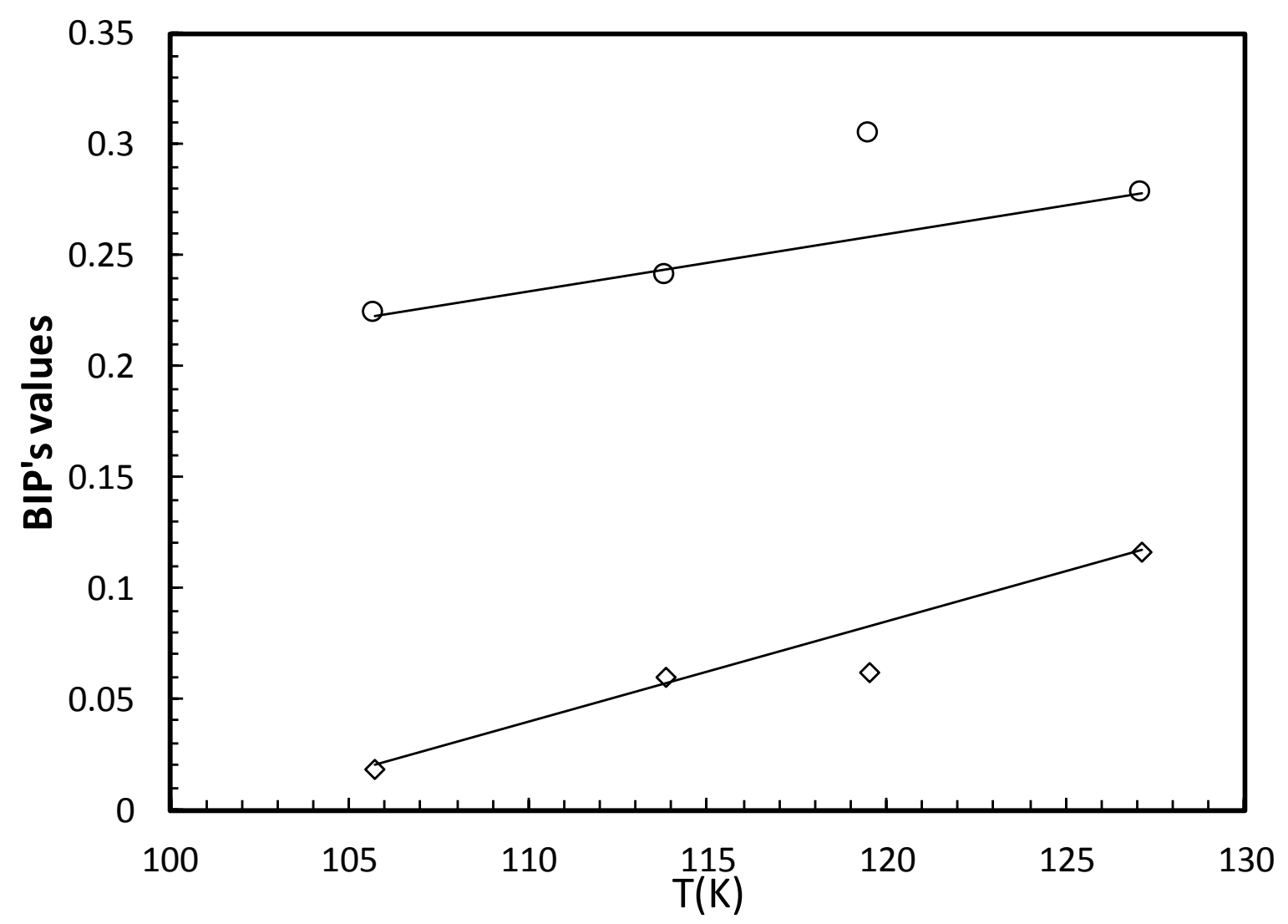

\section{Conclusions}

Phase equilibrium of binary mixtures $\mathrm{NO}$ with $\left(\mathrm{CO}, \mathrm{N}_{2}\right.$ or $\left.\mathrm{Ar}\right)$ for cryogenic air separation in this paper. New experimental VLE data for these three binary systems are presented at different temperatures. Experimental data for these systems have not been previously reported in the open literature at the studied temperature. The experimental setup using a 'staticanalytic' method is described and the uncertainties concerning the calibrations of pressure, temperature and gas chromatography detector are also given. The measured data were correlated using the PR-EoS with different mixing rules (classical, Wong-Sandler and HuronVidal) in function of the system studied. The new experimental data obtained in this work were used to adjust the binary interaction parameters and the chosen models seems to be adequate to fit these types of component and mixtures at these temperature conditions. As future work, we will be focusing on the improvement of PR-EoS in order to represent the thermodynamic behavior of air components. 


\section{Acknowledgments}

This work was funded by Chevron, Linde, GALP, OMV, PETEX, Statoil, TOTAL and UK National Grid, whose support is gratefully acknowledged. 


\section{List of figures}

Figure 1. Phase diagrams (P-x-y) for Ar (1) - NO (2) mixture (symbols: this work, $\square: 146.42$ $\mathrm{K}$, ○: $135.80 \mathrm{~K}$, Black lines: PR-EoS with a temperature dependent BIP).

Figure 2. Phase diagrams (P-x-y) for CO (1) - NO (2) mixture (symbols: this work, $\square: 127.32$ $\mathrm{K}, \circ: 105.89 \mathrm{~K}$, Black lines: PR-EoS with a temperature dependent BIP).

Figure 3. Phase diagrams (P-x-y) for $\mathrm{N}_{2}$ (1) - NO (2) mixture (symbols: experimental work, $\square$ : data measured in this work at $127.14 \mathrm{~K}$, ०: data measured in this work at $105.69 \mathrm{~K}, \times$ : Data from Scheunemann and Wagner measured at $119.55 \mathrm{~K}^{18}$, +: Data from Scheunemann and Wagner measured at $113.85 \mathrm{~K}^{18}$, Black lines: PR- EoS with a temperature dependent BIP).

Figure 4. BIP's values with PR-WS-Wilson EoS as function of temperature. (symbols: experimental work, $\circ: \tau 12, \square: \tau 21)$ for $\mathrm{N}_{2}(1)$ - $\mathrm{NO}(2)$ mixture.

\section{List of tables}

Table 1: Example of Air composition from Arpentinier et al. ${ }^{1}$.

Table 2: Details of the chemicals.

Table 3. Critical parameters, acentric factor and Mathias-Copeman Coefficients for the $\mathrm{PR}^{10}$.

Table 4. Vapor-liquid equilibrium pressures and phase compositions for Ar (1) - NO (2) mixture (composition: $y$ for Vapor phase and $x$ for liquid phase, $n$ : samples number).

Table 5. BIP values and deviations obtained in fitting experimental VLE data with PR-EoS (bubble pressure calculation) for $\operatorname{Ar}(1)$ - NO (2) mixture.

Table 6. Vapor-liquid equilibrium pressures and phase compositions for CO (1) - NO (2) mixture (composition: $y$ for Vapor phase and $x$ for liquid phase, $n$ : samples number).

Table 7. BIP values and deviations obtained in fitting experimental VLE data with PR-EoS (bubble pressure calculation), PR-WS-NRTL EoS (with non-randomness parameter $\alpha=0.3$ ) and PR-HV-Wilson EoS for CO(1) - NO (2) mixture.

Table 8. Vapor-liquid equilibrium pressures and phase compositions for $\mathrm{N}_{2}$ (1) - NO (2) mixture (composition: $y$ for Vapor phase and $x$ for liquid phase, $n$ : samples number).

Table 9. BIP values and deviations obtained in fitting experimental VLE data with PR-EoS (bubble pressure calculation), PR-WS-NRTL EoS (with non-randomness parameter $\alpha=0.3$ ) and PR-HV-Wilson EoS for $\mathrm{N}_{2}(1)$ - NO (2) mixture. 
Table 1: Example of Air composition from Arpentinier et al. ${ }^{1}$.

\begin{tabular}{c|c}
\hline Component & Volumetric composition \\
\hline & Fixed components \\
\hline $\mathrm{N}_{2}$ & $78.084 \pm 0.004 \%$ \\
\hline $\mathrm{O}_{2}$ & $20.964 \pm 0.002 \%$ \\
\hline $\mathrm{Ar}$ & $0.934 \pm 0.001 \%$ \\
\hline $\mathrm{CO}_{2}$ & $0.033 \pm 0.003 \%$ \\
\hline $\mathrm{Ne}$ & $1.8 \pm 0.04 \mathrm{ppm}$ \\
\hline $\mathrm{He}$ & $5.2 \pm 0.05 \mathrm{ppm}$ \\
\hline $\mathrm{Kr}$ & $1.14 \pm 0.01 \mathrm{ppm}$ \\
\hline $\mathrm{Xe}$ & $0.086 \pm 0.001 \mathrm{ppm}$ \\
\hline $\mathrm{H}_{2}$ & $0.05 \mathrm{ppm}$ \\
\hline Impurities (In ambient air, including dust, pollen and local \\
\hline $\mathrm{H}_{2} \mathrm{O}$ & pollutants.) \\
\hline $\mathrm{CH}$ & $0.1-2.8 \%$ \\
\hline $\mathrm{CO}$ & $1-6 \mathrm{ppm}$ \\
\hline $\mathrm{SOx}$ & $0.06-1 \mathrm{ppm}$ \\
\hline $\mathrm{NOx}_{\mathrm{O}}$ & $0.1-1.0 \%$ \\
\hline $\mathrm{O}_{3}$ & $0.52 \mathrm{ppm}$ \\
\hline $\mathrm{Rn}$ & $0.01-1 \mathrm{ppm}$ \\
\hline & $6 \times 10^{-3} \mathrm{ppq}$ \\
\hline
\end{tabular}


Table 2: Details of the chemicals.

\begin{tabular}{cccc}
\hline Chemical & Symbol & CAS number & Purity/volume\% (by weighing) \\
\hline Argon & $\mathrm{Ar}$ & $7440-37-1$ & 99.999 \\
Nitrogen & $\mathrm{N}_{2}$ & $7727-37-9$ & 99.995 \\
Carbon dioxide & $\mathrm{CO}$ & $630-8-0$ & 99.995 \\
Nitric oxide & $\mathrm{NO}$ & $10102-43-9$ & 99.000 \\
\hline
\end{tabular}


Table 3. Critical parameters, acentric factors and Mathias-Copeman Coefficients for the PR-EoS ${ }^{10}$.

\begin{tabular}{ccccccc}
\hline Chemical & $\boldsymbol{T}_{\boldsymbol{c}} / \mathbf{K}$ & $\boldsymbol{P}_{\boldsymbol{c}} / \mathbf{M P a}$ & $\boldsymbol{\omega}$ & $\boldsymbol{M C 1}$ & $\boldsymbol{M C 2}$ & $\boldsymbol{M C 3}$ \\
\hline $\mathrm{Ar}$ & 150.86 & 4.8980 & 0 & 0.397483 & -0.282393 & 0.796288 \\
$\mathrm{~N}_{2}$ & 126.20 & 3.4000 & 0.0377 & 0.448322 & -0.156813 & 0.468652 \\
$\mathrm{CO}$ & 132.92 & 3.4990 & 0.0481 & 0.451344 & -0.0791691 & 0.464029 \\
$\mathrm{NO}$ & 180.15 & 6.4800 & 0.5829 & 1.153810 & 0.243750 & -0.043201 \\
\hline
\end{tabular}


Table 4. Vapor-liquid equilibrium pressures and phase compositions for Ar (1) - NO (2) mixture (composition: $\mathrm{y}$ for vapor phase and $\mathrm{x}$ for liquid phase, $\mathrm{n}$ : samples number). $\mathrm{U}(\mathrm{T})=0.1 \mathrm{~K}, \mathrm{U}(\mathrm{P})=0.005 \mathrm{MPa}$.

\begin{tabular}{|c|c|c|c|c|c|}
\hline \multicolumn{6}{|c|}{$T / K=135.80$} \\
\hline $\mathrm{P} / \mathrm{MPa}$ & $y_{1}$ & $x_{1}$ & $U\left(y_{1}\right)$ & $\mathbf{U}\left(\mathbf{x}_{1}\right)$ & $n y_{1} ; n x_{1}$ \\
\hline 0.4109 & 0 & 0 & & & \\
\hline 0.6432 & 0.3613 & 0.0282 & $2 \mathrm{E}-04$ & $1 \mathrm{E}-04$ & $4 ; 6$ \\
\hline 0.8844 & 0.5431 & 0.0636 & $2 \mathrm{E}-04$ & $1 \mathrm{E}-04$ & $6 ; 5$ \\
\hline 1.0634 & 0.6173 & 0.0944 & $3 \mathrm{E}-04$ & $1 \mathrm{E}-04$ & $5 ; 7$ \\
\hline 1.4012 & 0.7006 & 0.173 & $2 \mathrm{E}-04$ & $2 \mathrm{E}-03$ & $6 ; 7$ \\
\hline 1.7597 & 0.768 & 0.312 & $1 \mathrm{E}-03$ & $1 \mathrm{E}-04$ & $6 ; 8$ \\
\hline 1.9230 & 0.788 & 0.392 & $1 \mathrm{E}-03$ & $4 \mathrm{E}-03$ & $4 ; 4$ \\
\hline 2.0315 & 0.809 & 0.478 & $1 \mathrm{E}-03$ & 4E-04 & $6 ; 6$ \\
\hline 2.1587 & 0.831 & 0.581 & $1 \mathrm{E}-03$ & $5 E-04$ & $5 ; 4$ \\
\hline 2.2484 & 0.851 & 0.671 & $1 \mathrm{E}-03$ & $2 \mathrm{E}-04$ & $6 ; 6$ \\
\hline 2.6056 & 1 & 1 & & & \\
\hline \multicolumn{6}{|c|}{$T / K=146.22$} \\
\hline 0.9878 & 0 & 0 & & & \\
\hline 1.5678 & 0.36283 & 0.0698 & $3 \mathrm{E}-05$ & 9E-04 & $6 ; 4$ \\
\hline 1.7377 & 0.4235 & 0.0924 & $1 \mathrm{E}-04$ & $2 \mathrm{E}-03$ & $6 ; 5$ \\
\hline 2.0521 & 0.51394 & 0.1475 & 7E-05 & $1 \mathrm{E}-03$ & $7 ; 5$ \\
\hline 2.5374 & 0.61724 & 0.2698 & $4 \mathrm{E}-05$ & $3 E-03$ & $6 ; 7$ \\
\hline 3.0786 & 0.70481 & 0.4680 & $3 \mathrm{E}-05$ & $4 \mathrm{E}-03$ & $6 ; 6$ \\
\hline 3.2953 & 0.74408 & 0.5728 & $2 \mathrm{E}-05$ & $3 \mathrm{E}-03$ & $4 ; 5$ \\
\hline 3.5934 & 0.8028 & 0.7120 & $1 \mathrm{E}-04$ & $1 \mathrm{E}-03$ & $6 ; 5$ \\
\hline 3.8280 & 0.8617 & 0.8206 & $1 \mathrm{E}-04$ & $2 \mathrm{E}-03$ & $5 ; 4$ \\
\hline 4.0289 & 1 & 1 & & & \\
\hline
\end{tabular}


Table 5. BIP values and deviations obtained in fitting experimental VLE data with PR-EoS (bubble pressure calculation) for $\mathrm{Ar}(1)$ - NO (2) mixture.

PR-EoS with classical mixing rules

\begin{tabular}{c|ccc}
\hline T/ K & kij & AAD P (\%) & AAD y1 (\%) \\
\hline 135.80 & 0.1144 & 1.68 & 2.20 \\
146.22 & 0.1247 & 1.05 & 1.74 \\
no temperature dependency & 0.1177 & 1.86 & 1.30 \\
\hline
\end{tabular}


Table 6. Vapor-liquid equilibrium pressures and phase compositions for CO (1) - NO (2) mixture (composition: $\mathrm{y}$ for vapor phase and $\mathrm{x}$ for liquid phase, $\mathrm{n}$ : samples number $) \mathrm{U}(\mathrm{T})=0.1 \mathrm{~K}, \mathrm{U}(\mathrm{P})=0.005 \mathrm{MPa}$.

\begin{tabular}{|c|c|c|c|c|c|}
\hline \multicolumn{6}{|c|}{$T / K=105.89$} \\
\hline $\mathrm{P} / \mathrm{MPa}$ & $\mathbf{y}_{1}$ & $x_{1}$ & $\mathrm{U}\left(\mathrm{y}_{1}\right)$ & $\mathrm{U}\left(\mathrm{x}_{1}\right)$ & $\mathrm{ny}_{1} ; \mathrm{nx}_{1}$ \\
\hline 0.0136 & 0 & 0 & & & \\
\hline 0.7847 & 0.99460 & 0.9607 & $4 \mathrm{E}-05$ & $1 \mathrm{E}-04$ & $4 ; 4$ \\
\hline 0.8026 & 0.99632 & 0.9776 & 4E-05 & 2E-04 & $4 ; 5$ \\
\hline 0.7905 & 0.99508 & 0.9653 & $2 \mathrm{E}-05$ & $3 \mathrm{E}-04$ & $4 ; 4$ \\
\hline 0.3739 & 0.9671 & 0.10236 & 7E-04 & $6 \mathrm{E}-05$ & $4 ; 5$ \\
\hline 0.4236 & 0.97249 & 0.1270 & $1 \mathrm{E}-05$ & $5 \mathrm{E}-04$ & $4 ; 5$ \\
\hline 0.4947 & 0.97742 & 0.1727 & $3 \mathrm{E}-05$ & 9E-04 & $4 ; 6$ \\
\hline 0.6552 & 0.98341 & 0.442 & 7E-05 & $1 \mathrm{E}-03$ & $5 ; 5$ \\
\hline 0.6930 & 0.98489 & 0.624 & $4 \mathrm{E}-05$ & $3 \mathrm{E}-03$ & $4 ; 5$ \\
\hline 0.7141 & 0.98588 & 0.729 & $3 \mathrm{E}-05$ & 4E-03 & $4 ; 5$ \\
\hline 0.7200 & 0.98707 & 0.762 & $2 \mathrm{E}-05$ & $3 \mathrm{E}-03$ & $3 ; 5$ \\
\hline 0.7300 & 0.9881 & 0.817 & $1 \mathrm{E}-04$ & $1 \mathrm{E}-03$ & $4 ; 5$ \\
\hline 0.8300 & 1 & 1 & & & \\
\hline \multicolumn{6}{|c|}{$T / K=127.32$} \\
\hline 0.1883 & 0 & 0 & & & \\
\hline 0.3852 & 0.5034 & 0.0198 & $5 \mathrm{E}-04$ & $4 \mathrm{E}-04$ & $5 ; 4$ \\
\hline 0.5011 & 0.618 & 0.0329 & $1 \mathrm{E}-03$ & $2 \mathrm{E}-04$ & $4 ; 6$ \\
\hline 0.8348 & 0.754 & 0.0763 & $2 \mathrm{E}-03$ & $5 \mathrm{E}-04$ & $6 ; 5$ \\
\hline 1.0907 & 0.8092 & 0.1190 & 7E-04 & $2 \mathrm{E}-04$ & $4 ; 5$ \\
\hline 1.4696 & 0.85953 & 0.211 & $3 \mathrm{E}-05$ & $1 \mathrm{E}-03$ & $4 ; 5$ \\
\hline 1.7178 & 0.8815 & 0.314 & $2 \mathrm{E}-04$ & $1 \mathrm{E}-03$ & $5 ; 5$ \\
\hline 1.9145 & 0.8946 & 0.449 & $3 \mathrm{E}-04$ & $1 \mathrm{E}-03$ & $5 ; 9$ \\
\hline 2.0645 & 0.9018 & 0.5794 & $2 \mathrm{E}-04$ & $2 \mathrm{E}-04$ & $4 ; 4$ \\
\hline 2.1381 & 0.9084 & 0.6493 & $2 \mathrm{E}-04$ & $2 \mathrm{E}-04$ & $4 ; 4$ \\
\hline 2.1879 & 0.9137 & 0.7082 & $5 \mathrm{E}-04$ & $2 \mathrm{E}-04$ & $4 ; 4$ \\
\hline 2.2484 & 0.92010 & 0.74575 & 7E-05 & $9 \mathrm{E}-05$ & $4 ; 5$ \\
\hline 2.4190 & 0.9421 & 0.86122 & $2 \mathrm{E}-04$ & $4 \mathrm{E}-05$ & $4 ; 5$ \\
\hline 2.5146 & 0.9590 & 0.9157 & $3 E-04$ & $5 \mathrm{E}-04$ & $4 ; 8$ \\
\hline 2.6820 & 1 & 1 & & & \\
\hline
\end{tabular}


Table 7. BIP values and deviations obtained in fitting experimental VLE data with PR-EoS (bubble pressure calculation), PR-WS-NRTL EoS (with non-randomness parameter $\alpha=0.3$ ) and PR-HV-Wilson EoS for CO (1) NO (2) mixture.

\begin{tabular}{|c|c|c|c|c|c|c|c|c|}
\hline \multirow[b]{2}{*}{$\mathrm{T} / \mathrm{K}$} & \multicolumn{3}{|c|}{ PR-EoS with classical mixing rule } & \multicolumn{5}{|c|}{ PR-WS-NRTL EOS } \\
\hline & kij & AAD P (\%) & AAD y1(\%) & kij & $\tau_{12} /{\mathrm{J} . \mathrm{mol}^{-1}}^{-1}$ & $\tau_{21} /{\mathrm{J} . \mathrm{mol}^{-1}}^{-1}$ & AAD P (\%) & AAD y1 (\%) \\
\hline 105.89 & -0.0081 & 4.89 & 0.49 & -0.34795 & 3178.80 & 1235.00 & 1.60 & 0.53 \\
\hline 127.32 & 0.0374 & 4.52 & 0.93 & 0.24814 & 61.69 & 1304.80 & 1.35 & 0.73 \\
\hline
\end{tabular}

\begin{tabular}{c|cccc}
\cline { 2 - 5 } & \multicolumn{4}{c}{ PR-HV-Wilson EoS } \\
\hline T/ K & $\tau_{\mathbf{1 2}}$ & $\boldsymbol{\tau}_{\mathbf{2 1}}$ & AAD P (\%) & AAD y1(\%) \\
\hline 105.89 & 0.30286 & 0.14462 & 1.0 & 0.32 \\
127.32 & 0.14462 & 0.1164 & 0.89 & 1.55 \\
\hline
\end{tabular}


Table 8. Vapor-liquid equilibrium pressures and phase compositions for $\mathrm{N}_{2}$ (1) - NO (2) mixture (composition: $\mathrm{y}$ for vapor phase and $\mathrm{x}$ for liquid phase, $\mathrm{n}$ : samples number). $\mathrm{U}(\mathrm{T})=0.1 \mathrm{~K}, \mathrm{U}(\mathrm{P})=0.005 \mathrm{MPa}$.

\begin{tabular}{|c|c|c|c|c|c|}
\hline \multicolumn{6}{|c|}{$T / K=105.69$} \\
\hline $\mathrm{P} / \mathrm{MPa}$ & $y_{1}$ & $x_{1}$ & $\mathrm{U}\left(\mathrm{y}_{1}\right)$ & $\mathbf{U}\left(\mathbf{x}_{1}\right)$ & $n y_{1} ; n x_{1}$ \\
\hline 0.3008 & 0.9713 & 0.0328 & 3E-04 & $4 \mathrm{E}-04$ & $5 ; 4$ \\
\hline 0.3558 & 0.9751 & & $3 \mathrm{E}-04$ & & 4 \\
\hline 0.4653 & 0.9794 & & $2 \mathrm{E}-04$ & & 5 \\
\hline 0.5379 & 0.9828 & 0.0774 & $2 \mathrm{E}-04$ & $8 \mathrm{E}-04$ & $4 ; 5$ \\
\hline 0.6207 & 0.9845 & 0.0912 & $2 \mathrm{E}-04$ & 9E-04 & $5 ; 5$ \\
\hline 0.7078 & 0.9893 & 0.105 & $1 \mathrm{E}-04$ & $1 \mathrm{E}-03$ & $3 ; 4$ \\
\hline 0.8226 & 0.99222 & 0.147 & $9 \mathrm{E}-05$ & $1 \mathrm{E}-03$ & $4 ; 4$ \\
\hline 0.8555 & 0.99244 & 0.159 & $9 \mathrm{E}-05$ & $2 \mathrm{E}-03$ & $4 ; 5$ \\
\hline 0.8922 & 0.99410 & 0.180 & $7 \mathrm{E}-05$ & $2 \mathrm{E}-03$ & $3 ; 4$ \\
\hline 0.9474 & 0.99447 & 0.225 & $6 \mathrm{E}-05$ & $2 \mathrm{E}-03$ & $3 ; 5$ \\
\hline 0.9791 & 0.99304 & 0.259 & $8 \mathrm{E}-05$ & $2 \mathrm{E}-03$ & $3 ; 4$ \\
\hline \multicolumn{6}{|c|}{$\mathrm{T} / \mathrm{K}=127.14$} \\
\hline 0.5568 & 0.667 & 0.0236 & $3 \mathrm{E}-03$ & $3 \mathrm{E}-04$ & $5 ; 6$ \\
\hline 0.8751 & 0.783 & 0.0474 & $2 \mathrm{E}-03$ & $5 \mathrm{E}-04$ & $5 ; 6$ \\
\hline 1.1304 & 0.829 & 0.0695 & 2E-03 & 7E-04 & $5 ; 9$ \\
\hline 1.4500 & 0.862 & 0.104 & $1 \mathrm{E}-03$ & $1 \mathrm{E}-03$ & $5 ; 6$ \\
\hline 1.7464 & 0.879 & 0.141 & $1 \mathrm{E}-03$ & $1 \mathrm{E}-03$ & $5 ; 5$ \\
\hline 1.9861 & 0.891 & 0.184 & $1 \mathrm{E}-03$ & $2 \mathrm{E}-03$ & $5 ; 5$ \\
\hline 2.3211 & 0.906 & 0.282 & $1 \mathrm{E}-03$ & $2 \mathrm{E}-03$ & $6 ; 5$ \\
\hline 2.5660 & 0.9130 & 0.450 & 9E-04 & $3 \mathrm{E}-03$ & $5 ; 7$ \\
\hline 2.6573 & 0.9151 & 0.561 & 9E-04 & $3 \mathrm{E}-03$ & $3 ; 5$ \\
\hline 2.7213 & 0.9185 & 0.632 & $8 \mathrm{E}-04$ & $3 \mathrm{E}-03$ & $4 ; 9$ \\
\hline 2.7482 & 0.9206 & 0.644 & $8 \mathrm{E}-04$ & $3 \mathrm{E}-03$ & $3 ; 4$ \\
\hline 2.7944 & 0.9221 & 0.703 & $8 \mathrm{E}-04$ & $2 \mathrm{E}-03$ & $3 ; 5$ \\
\hline
\end{tabular}


Table 9. BIP values and deviations obtained in fitting experimental VLE data with PR-EoS (bubble pressure calculation), PR-WS-NRTL EoS (with non-randomness parameter $\alpha=0.3$ ) and PR-HV-Wilson EoS for $\mathrm{N}_{2}(1)$ NO (2) mixture.

\begin{tabular}{c|ccc|ccccc}
\cline { 2 - 10 } \multicolumn{1}{c|}{ PR-EoS with classical mixing rule } & \multicolumn{5}{c}{ PR-WS-NRTL EoS } \\
\hline T/ K & kij & AAD P (\%) & AAD y1(\%) & kij & $\tau_{\mathbf{1 2}} /$ J.mol-1 & $\tau_{\mathbf{2 1}} /$ J.mol-1 & AAD P (\%) & AAD y1 (\%) \\
105.69 & -0.0004 & 8.02 & 1.31 & 0.0803 & 974.50 & 1244.80 & 1.67 & 1.01 \\
113.83 & 0.0241 & 6.81 & 0.63 & 0.2368 & 403.22 & 1307.00 & 1.77 & 0.08 \\
119.56 & 0.0307 & 7.25 & 0.90 & 0.2198 & 644.32 & 1034.50 & 1.75 & 0.09 \\
127.14 & 0.0430 & 5.52 & 2.74 & 0.2780 & -138.28 & 1843.70 & 0.29 & 0.78 \\
\hline
\end{tabular}

\begin{tabular}{c|cccc}
\cline { 2 - 5 } \multicolumn{2}{c}{} & \multicolumn{4}{c}{ PR-HV-Wilson EoS } \\
\hline T/ K & $\tau_{\mathbf{1 2}}$ & $\tau_{\mathbf{2 1}}$ & AAD P (\%) & AAD y1(\%) \\
\hline 105.69 & 0.2233 & 0.0186 & 3.30 & 1.14 \\
113.83 & 0.2413 & 0.0598 & 1.69 & 0.58 \\
119.56 & 0.3051 & 0.0619 & 3.07 & 1.08 \\
127.14 & 0.2782 & 0.1164 & 1.94 & 3.14 \\
\hline
\end{tabular}




\section{References}

(1) Arpentinier, P., Cavani F., Trifirò, F. The technology of catalytic oxidations, Paris: Editions Technip, 2001.

(2) Baba-Ahmed A., Guilbot P., Richon, D. New equipment using a static analytic method for the study of vapour-liquid equilibria at temperatures down to $77 \mathrm{~K}$, Fluid Phase Equilib. 1999, 166, 225-236.

(3) De Stefani, V., Baba-Ahmed, A., Valtz, A., Meneses, D., Richon, D. Solubility measurements for carbon dioxide and nitrous oxide in liquid oxygen at temperatures down to 90 K. Fluid Phase Equilib. 2002, 200, 19-30.

(4) Houssin-Agbomson, D., Coquelet, C., Richon, D., Arpentinier, P. Equipment using a "static-analytic" method for solubility measurements in potentially hazardous binary mixtures under cryogenic temperatures, Cryogenics 2010, 50, 248-256.

(5) Houssin-Agbomson, D., Coquelet, C., Arpentinier, P., Delcorso, F., Richon. D. Equilibrium data for the oxygen + propane binary system at temperatures of $(110.22,120.13$, 130.58 and 139.95) K. J. Chem. Eng. Data 2010, 55, 4412-4415.

(6) Coquelet, C., Stringari, P., Hajiw, M., Gonzalez, A., Pereira, L., Nazeri, M., Burgass, R., Chapoy, A. Transport of $\mathrm{CO}_{2}$ : Presentation of New Thermophysical Property Measurements and Phase Diagrams, Energy Procedia 2017, 114, 6844-6859.

(7) French patent deposed by Armines 2003, Procédé et dispositif pour prélever des microéchantillons d'un fluide sous pression contenu dans un container.

(8) Taylor, B.N., Kuyatt, C.E. Guidelines for evaluating and expressing the uncertainty of NIST measurement results, National Institute of Standards and Technology, Gaithersburg, MD, 1994

(9) Zhang, F., Théveneau, P., El Ahmar, E., Canet, X., Soo, C.-B., Coquelet, C. An improved static-analytic apparatus for vapor-liquid equilibrium (PTxy) measurement using modified in-situ samplers, Fluid Phase Equilib. 2016, 409, 425-433.

(10) Component plus software, version, 3.0.0.0, Prosim SA, France, 1999.

(11) Peng, D.Y., Robinson, D.B. A new two constant equation of state. Ind. Eng. Chem. Fundam. 1976, 15, 59-64.

(12) Mathias, P. M., Copeman, T. W. Extension of the Peng-Robinson Equation of State to Complex Mixtures: Evaluation of Various Forms of the Local Composition Concept. Fluid Phase Equilib. 1983, 13, 91-108.

(13) Van Der Waals, J. D. On the continuity of the gaseous and liquid state. Ph.D. Thesis, Leiden University, Leiden, The Netherlands, 1873.

(14) Wong, D. S. H., Sandler, S. I. A Theoretically Correct Mixing Rules for Cubic Equations of State. AIChE J. 1992, 38, 671-680.

(15) Renon, H., Prausnitz, J. M. Local Composition in Thermodynamic Excess Function for Liquid Mixtures. AIChE J. 1968, 14,135-144.

(16) Huron, M. J., Vidal, J. New Mixing Rules in Simple Equations of State for Representing Vapor-Liquid Equilibria of Strongly non-ideal Mixtures, Fluid Phase Equilib. 1979, 3, 255271.

(17) Wilson, G. M. Vapor-Liquid Equilibrium. XI. A New Expression for the Excess Free Energy of Mixing, J. Am. Chem. Soc. 1964, 127-130.

(18) Scheunemann, U., Wagner, H. G. Eine Apparatur zur Bestimmung von TieftemperaturFlüssigkeits-Dampf-Gleichgewichten und Messungen im System $\mathrm{N}_{2}-\mathrm{NO}$, Berichte der Bunsengesellschaft für physikalische Chemie 1985, 89, 1285-1292. 
For Table of Contents Only:
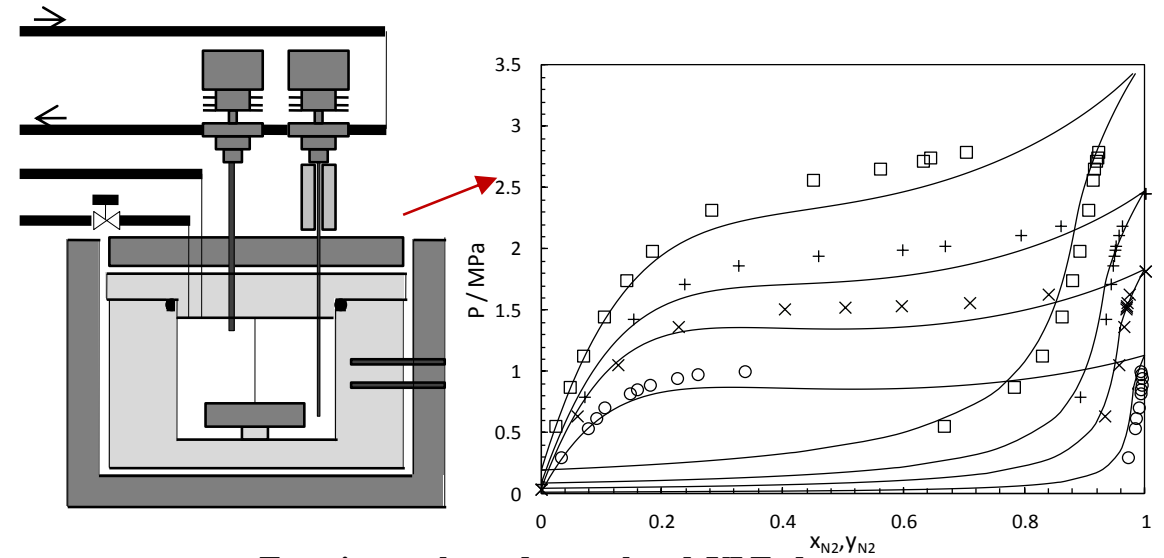

Experimental and correlated VLE data 